\title{
EXPLORING THE ROLE OF SELF-EFFICACY, PLAYFULNESS, AND CREATIVE SELF-EFFICACY IN INFORMATION SYSTEMS DEVELOPMENT
}

\author{
Ananth Chiravuri, American University of Sharjah, achiravuri@aus.edu \\ Paul J. Ambrose, University of Wisconsin - Whitewater, Email: ambrosep@uww.edu
}

\begin{abstract}
In this paper we argue that successful information systems development requires creative problem solving skills, and present two cognitive factors, selfefficacy, and creative self-efficacy, and one affective factor, playfulness, as three key personal factors that aid creative problem solving during information systems development (ISD). A research model to support our argument is constructed synthesizing relevant literature from social cognitive theory, IS success, and software quality research streams. A proposed methodology to test the research model and the research implications are also presented.
\end{abstract}

Keywords: Self-efficacy, Creative Self-efficacy, Playfulness, Information Systems Development, Software Quality Performance.

\section{INTRODUCTION}

Managing Information Systems (IS) human resources has been long recognized as one of the key management issues in the domain of information systems [8, 33, 34]. Two key economic and environmental trends pose a critical challenge to IS human resources management. First, organizations are under constant pressure to cut costs, and consequently, often downsize organizational functions such as information systems, which are perceived to be support rather than line functions. For example: Nokia is planning to reshuffle 700 employees in order to improve its focus and efficiency. Similarly SanDisk is planning to layoff 250 people and Motorola is cutting 3500 jobs to remain profitable [32]. Second, there is a shortage of well trained IS personnel [26, 27], which further exacerbates the problem. Typically when firms downsize or when there is a shortage of skilled IS workers, IS executives are forced to staff projects with fewer people, who now require a broad range of skills to fulfill the needs of the project. But simultaneously, IS executives are often faced with complex projects that cover a wide range of technologies "calling for greater and more specialized skills" [33, p. 480]. Consequently, IS executives and their project teams are often expected to deliver results under multiple constraints, forcing them to be creative.
So, how do IS personnel manage in such demanding work situations? What skills and knowledge do they need to adapt to produce superior performance under such conditions? Traditionally, IS personnel are expected to posses a blend of technical and business skills to succeed with a stronger focus on technical knowledge [4, 41]. Technical and business skills are essential and necessary for conceptualizing, and implementing IS projects. But these skills are not sufficient for successful completion of IS projects in a climate where there is an increasing need for creative solutions. We posit that in addition to technical and business skills, IS personnel need to possess appropriate psycho-social related personal factors that help foster creativity.

However, IS research has not adequately addressed the inclusion of important personal factors such as cognitive, affective, and conative factors in the skill set required of an IS worker. These personal factors, which reflect the thoughts, emotions, and intentions of a person, have been shown to affect the person's job related behavior [6, 14]. Further these are independent of technical and managerial skills that IS personnel are expected to posses. Cognitive, affective, and conative factors of IS personnel can hence potentially affect the job related performance of IS personnel ${ }^{\mathrm{a}}$ and consequently, the quality of systems developed and maintained.

In this paper we argue for the inclusion of two key cognitive factors - self-efficacy, and creative selfefficacy, and one affective factor - playfulness, in an IS personnel's skill set to help cope with the demands of their profession. Specifically, our research agenda in this paper is to theoretically argue for the consideration of the above cognitive and affective factors, develop an overarching conceptual model to depict the impact of these factors on IS development, and propose a research plan for empirical testing of our conceptual model. Accordingly, the rest of the paper is organized as follows. In the next section, we discuss the relevant theoretical background for this research. In the section following, we present our research model and the theoretical frameworks used to construct the model. In the section following, we outline the proposed research methodology. The final 
section concludes with discussions on implications of this research.

\section{THEORETICAL BACKGROUND}

Creativity, both at the organizational and at the individual level, has emerged as an important factor in managing organizations as it helps firms respond effectively in today's highly complex and volatile environment [31], Creativity helps organizations differentiate themselves from their competitors [39]. Studies have indicated that creativity is useful in establishing and maintaining competitive advantage $[18,24]$. Creativity has also been recognized to be important in the IS literature [17, 44]. For example, research has indicated that creativity can be important in all aspects of IS development [16]. This view is shared by Cooper [15], who identified individual and group characteristics that produce a creativity fostering climate during IS requirements gathering and analysis, and logical design phases. In addition, IS research has focused on creativity through the study of creativity support systems [31, 50] and has examined the effects of group memory on creativity [39].

Although there has been progress, few studies in the IS domain have examined creativity [2, 44], or the role of constructs at the individual level that lead to creativity [see 15 for an exception]. It is important to know what factors cause creativity at an individual level because of the need for IS managers to identify and appropriately staff highly creative individuals early in the IS development process to ensure success. Further, an identification of the factors that cause creativity also creates room for managing these factors appropriately to realize desired work related results. In spite of a lacuna of creativity research within the IS domain, the IS literature has noted the need for creativity in the information systems development (ISD) process [44], setting the motivation for this study.

We refer to the social cognitive theory (SCT) $[5,6,7]$ to identify factors that help foster creativity among individuals. Bandura [7], the original proponent of the social cognitive theory, identified salient cognitive (thoughts), affective (emotions), and conative (intentions) factors that influence a person's behavior including creative productivity. Among several personal factors that Bandura identified, selfefficacy, a cognitive factor, emerged as a key influencing factor of behavior of individuals [7]. Self-efficacy refers to the belief of an individual in his or her capabilities to organize and execute the courses of action required to produce given attainments independent of skills possessed by that individual to complete the courses of action [6]. Empirical evidence for self-efficacy as a key predictor of behavior abounds in diverse research domains, including information systems [see 13 for a detailed literature review of self-efficacy studies in IS]. Though it has been argued that self-efficacy beliefs influence creativity because they impact the motivation and ability of individuals to engage in specific behavior [5, 7, 42], IS research has not focused on the creative aspect of behavior, instead focusing on other behaviors such as computer usage.

Further, seminal research, e.g. Ford [22, 23], indicated self-efficacy as a key motivational factor of creative action. This led to the development of a new construct called creative self-efficacy [42], specifically tailored to address creativity. Creative self-efficacy is the "belief one has in the ability to produce creative outcomes" [42, p. 1138]. Creative self-efficacy is different from self-efficacy because it is creativity specific [42]. In fact, creative selfefficacy has been found to predict creative performance beyond the predictive effects of job selfefficacy [42]. Also, self-efficacy has been shown to be a predictor of creative self-efficacy [42]. Theoretical and empirical support for creative selfefficacy has since been established, particularly in organizational behavior research [3, 12, 43, 47].

Playfulness is a construct that is closely related to creative self-efficacy. Playfulness is defined as the degree of cognitive spontaneity in a particular task situation, and describes an individual's tendency to be spontaneous, innovative, and imaginative in a task situation [49]. Prior studies have argued that playfulness impacts creativity [40] and have empirically confirmed it [25]. It has been further argued that playfulness results in subjective experiences like involvement, positive mood and satisfaction [19, 28]. Using the concept of playfulness, Webster and Martocchio [49] show microcomputer playfulness to be important to study because of its implications for IS success. For example, the article notes that "employees higher in microcomputer playfulness will view microcomputer interactions more positively than less playful employees and consequently will be more motivated to engage in microcomputer interactions in the future” [49, p. 202]. Playfulness is influenced by one's self-efficacy beliefs [30], and its impact on creativity, empirically substantiated [1, 30, 48, 49].

Social cognitive theory identifies encouragement (from peers and supervisors) enactive mastery (prior experience), vicarious experience, verbal persuasion 
(especially by respected mentors), physiological arousal, education level, and job complexity as key antecedents of an individual's self-efficacy beliefs.[7, 9, 29]. Accordingly, managing these antecedents is of paramount importance to ensure that an individual's cognitive and affective factors are aligned to produce superior job related behavior, including creative productivity. The research model developed in this paper includes these antecedent factors in addition to the personal factors discussed earlier, and proposes that software professionals' self-efficacy, playfulness, and creative self-efficacy are three key constructs that help generate creative information systems solutions that in turn lead to the development of quality information systems.

While the above arguments indicate that a software professional's self-efficacy, playfulness, and creative self-efficacy can individually impact ISD and the quality of systems developed, the collective impact of these constructs has not been addressed, particularly in an IS development context. Collectively, they may explain a higher variance in the dependent construct. However, these constructs may be highly correlated, suggesting that there is a substitution effect among these constructs. Consequently, we attempt to examine the complementary and substitution effects of self-efficacy, playfulness, and creative selfefficacy on information systems development.

\section{RESEARCH MODEL}

Figure 1 shows the research model indicating the research constructs and their relationships. Selfefficacy, creative self-efficacy, and playfulness are shown impacting software quality performance, a measure of ISD success. The model also depicts the antecedents of the three personal factors. While the research model is primarily built using social cognitive theory as the influencing theoretical framework, it also draws on the information systems success, and software quality research streams. The research model is further explicated in this section.

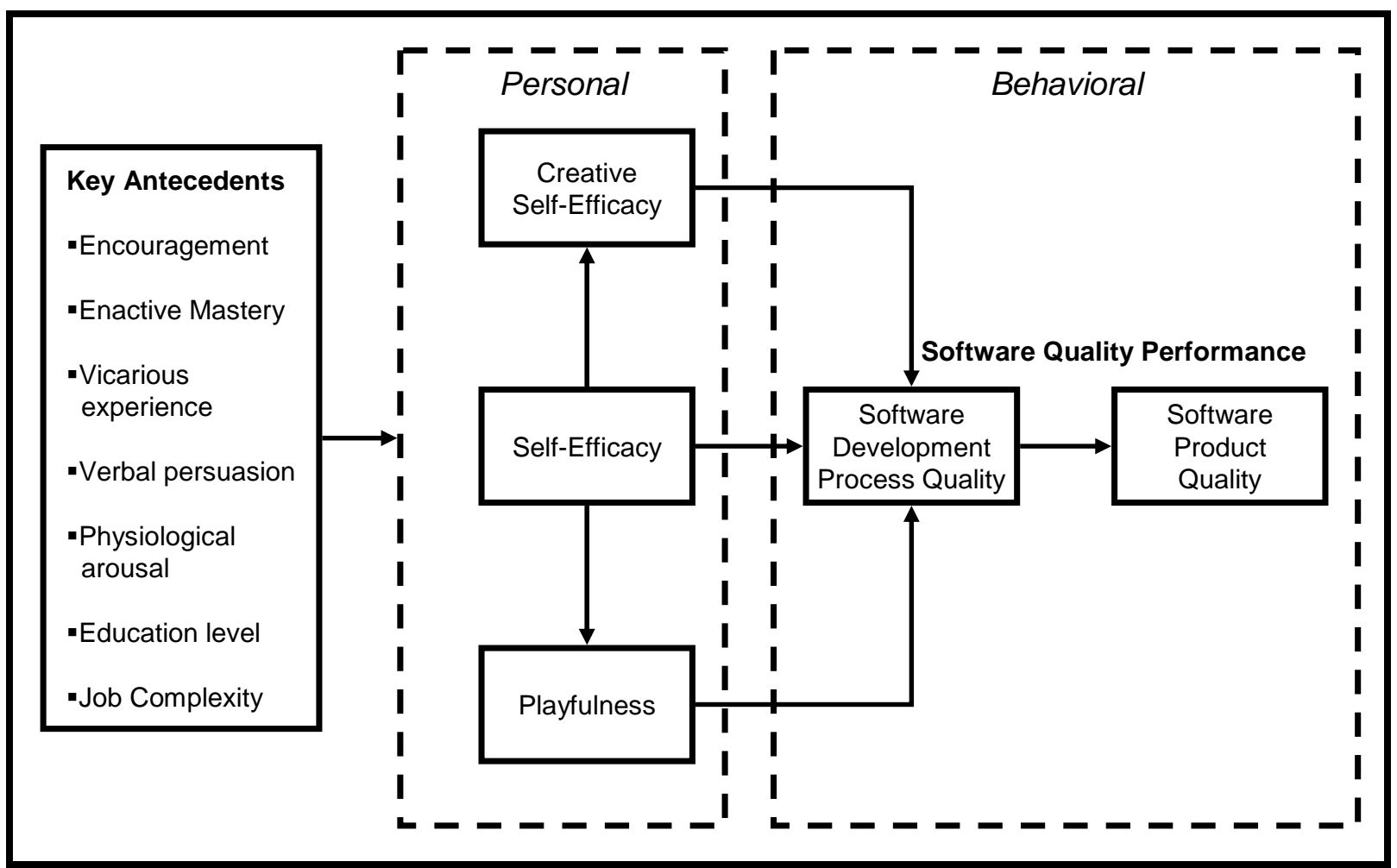

Figure 1: Research Model

\section{Social Cognitive Theory and its Implication for the Research Model}

The social cognitive theory $[5,6]$ premises a triadic reciprocal relationship among an individual's environment, personal factors, and behavior as shown in Figure 2. Our research model focuses on personal factors and behavior, or more specifically, creativity as a behavior. We include the three personal factors discussed earlier as the key factors that influence creative behavior for successful information systems 
development. The antecedents of self-efficacy are modeled as antecedents of creative self-efficacy, and playfulness as well, as these two factors are impacted by self-efficacy as discussed in the earlier section.

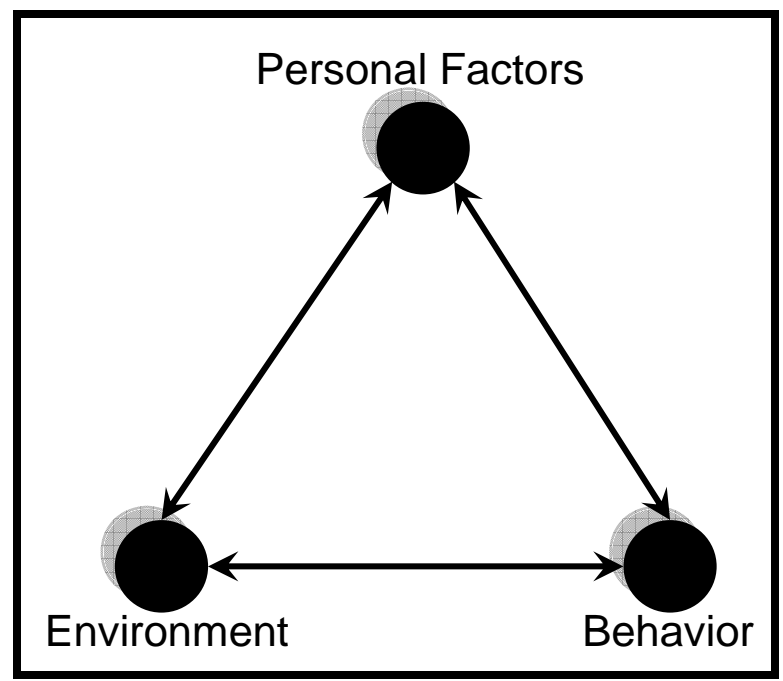

Figure 2. Triadic Reciprocity

It should be noted that social cognitive theory from social psychology is well established, and its validity empirically established in diverse research domains such as management, medicine, psychology, and education to name a few [29]. It has found favor with IS success researchers, and is one of the more popular theories of human thought and action in IS research [45]. Our focus is to integrate key constructs from this rich theoretical stream into one theoretical framework to examine the link between an IS personnel's cognitive framework and its impact on information systems development.

SCT allows for the measurement of behavior in terms of performance or productivity [13], a manifestation of behavior or action undertaken. Our model evaluates creative behavior in terms of successful information systems development, as ISD is considered a creative problem solving activity. Further, ISD largely consists of heuristic tasks - that is, tasks that do not have clear and readily identifiable paths to the solution [15]. Therefore, studies have noted that members in a team often use their prior experience to diagnose the design problem and possible solutions in ISD projects [38]. Such prior experience of team members leads to different approaches and triggers a generation of divergent and creative solutions which is necessary for effective ISD [35]. We argue that such experiences that lead to different solutions are a result of the playfulness, creative self-efficacy and self-efficacy of a member. These three personal factors are especially important since the success of ISD projects depends on acquiring and exploiting knowledge from multiple domains, the rationale being that an increase in the number of functional domains results in more ideas and increased associations among those ideas [20, 46] Information Systems Success Model and its
Implication for the Research Model

Specifically, we measure successful information systems development in terms of software quality performance. The choice of this performance measure is influenced by DeLone and McLean's [21] information systems success model, and is further elucidated for our research below.

DeLone and McLean's [21] information systems success model posits IS success is multi-dimensional consisting of six related constructs, namely, information quality, system quality, service quality, system utilization/usage, user satisfaction, and net benefits. DeLone and McLean developed a nomological model consisting of these six constructs where information quality, and system quality are considered precursors to other IS success constructs [see 21, and a subsequent 2003 update by DeLone and McLean in the Journal of Management Information Systems for a detailed literature review and support]. The IS success model is an overarching research framework that covers all aspect of systems success. In this research, we focus on information systems development and not its subsequent use, and as such, systems quality will be an appropriate measure of ISD success.

\section{Software Quality Research and its Implication for the Research Model}

Contemporary software quality research treats the software quality construct as multi-dimensional, and a distinct research stream within IS research has emerged to address software quality. Information systems quality, or more commonly referred to as software quality performance, consists of system development process quality and system product quality [36, 37]. Development process quality is the antecedent of product quality, and hence is a critical determinant of product quality [36, 37] and consequently information systems success [21].

The above focus of software quality performance, which includes both process and product quality, is known as the organizational approach to software quality management, influenced by total quality management (TQM) principles [see 36 for a more 
detailed discussion and literature review]. Our use of the term ISD refers to the systems development process, and our goal is to examine how the identified cognitive and affective factors can affect the creative problem solving needs of information systems development or the systems development process.

\section{RESEARCH METHODOLOGY}

The unit of analysis for our study would be the software developer, the key respondent for our research. Data would be collected through a survey of our key respondents. These software developers would be drawn from firms that have significantly downsized and those that have not downsized in the last 12 months. This would help establish if creative solutions were needed to adapt to a demanding work condition resulting from downsizing. We would also collect data on the projects that these developers worked on to establish ISD quality independent of the key respondents. A structured questionnaire containing items measuring our constructs, would be administered to software developers by obtaining prior consent from the IS departments where these developers work. The questionnaire will consist of items that will be used from previous studies wherever possible. Respondents will mark their agreement and disagreement with the statements on a 7-point scale with 1 being "strongly disagree" and 7 being "strongly agree”.

Self-efficacy measures would be modified for this study context from Compeau and Higgins' [14] instrument. Similarly, playfulness measures would be modified from Webster and Martocchio's [49] instrument, and finally, creative self-efficacy from Tierney and Farmer's [42] instrument. Items measuring software quality performance will be developed primarily from [36]. It should be noted that we have presented an overarching conceptual model, and that this model will be detailed during its operationalization. For example, software quality performance will be elaborated to capture various facets of systems development process quality, and software product quality.

Data will be analyzed using the Partial Least Squares (PLS) technique. Choice of PLS as the analysis technique is two fold. First, PLS is a second generation structural equation modeling technique that has a higher power to analyze moderating effects when compared to first generation regression methods such as moderated regression analysis [11]. Second, ours is a theory generating and not a theory confirming study, and in such situations PLS is the preferred analytical methodology [10]. Significant path coefficients between each exogenous construct and IS quality would indicate the presence of complementary effects. However, insignificant and unstable path coefficients would indicate substitution effects, as the instability would result from high levels of multi-collinearity among the exogenous constructs.

\section{DISCUSSION AND CONCLUSION}

In this paper we argued for the consideration of critical skills that can enable creativity that IS personnel should possess in addition to technical and business skills. To further our argument, we also developed a research model that can enable further academic discussion, and practitioner consideration, for managing IS human resources. This research has several contributions. First, this paper provides a pioneering research model that incorporates selfefficacy, creative self-efficacy, and playfulness in one integrated model to examine their collective impact on information systems development. IS research has acknowledged the importance of these factors in the past; however studies have not examined their collective impact in an IS development domain. Second, this study provides a research model and a research methodology to discern if the factors are complementary or substitutional. Third, this study aims to highlight to IS managers the importance of managing individual variables such as self-efficacy, creative self-efficacy and playfulness in the ISD process with implication for software quality. With commonly cited statistics that $50 \%$ of all software development projects fail mainly on account of inappropriate software development process management, this study provides key insights on how that process can be managed better. In other words, our study serves to reinforce the thought that the success of an ISD is dependent on creativity, an issue that deserves a much greater degree of attention especially during a downsizing and IS worker shortage era. We acknowledge that our model has not been empirically validated, but defer that exercise and also its refinement to a subsequent research endeavor.

\section{REFERENCES}

1. Agarwal, R. \& Karahanna, E. (2000). Time Flies When You're Having Fun: Cognitive Absorption and Beliefs About Information Technology Usage. MIS Quarterly, 24,(4), 665-694.

2. Amorosa, D. L. \& Couger, J. D. (1995). Developing Information Systems with Creativity Techniques: An Exploratory Study. Proceedings 
of 28th Annual Hawaii International Conference on System Sciences, Maui, Hawaii, 720 - 728.

3. Arendt, L. \& Mone, M. A. (2005). Funny Business: A Model of How Leaders' Humor Affects Followers' Creativity and Satisfaction. Proceedings of Academy of Management, Honolulu, Hawaii, 49.

4. Arnold, D. \& Niederman, F. (2001). IT The Global Work Force. Communications of the ACM, 44,(7), 30-33.

5. Bandura, A. (1977). Self-efficacy: Toward a unifying theory of behavioral change. Psychological Review, 84,(2), 191-215.

6. Bandura, A. (1986). Self Efficacy, Social foundations for Thought and Action: A Social Cognitive Theory, Englewood Cliffs, NJ: Prentice-Hall.

7. Bandura, A. (1997). Self Efficacy: The exercise of control, New York, NY: W. H. Freeman.

8. Brancheau, J. C., Janz, B. D., \& Wetherbe, J. C. (1996). Key issues in information systems management: 1994-95 SIM Delphi results. MIS Quarterly, 20,(2), 225.

9. Cameron, K. S., Freeman, S. J., \& Mishra, A. K. (1991). Best practices in white-collar downsizing: managing contradictions. Academy of Management Executive, 5,(3), 57-73.

10. Chin, W. W., "The Partial Least Square Approach to Structural Equation Modeling," in G. A. Marcoulides, ed., Modern Methods for Business Research, Mahwah, NJ: Lawrence Erlbaum Associates, 1998, pp. 150-170.

11. Chin, W. W., Marcolin, B. L., \& Newsted, P. R. (2003). A Partial Least Squares Latent Variable Modeling Approach for Measuring Interaction Effects: Results from a Monte Carlo Simulation Study and an Electronic-Mail Emotion/Adoption Study. Information Systems Research, 14,(2), 189-217.

12. Chua, R. Y. J. \& Iyengar, S. S. (2005). The Effects of Choice, Goal and Creative Selfefficacy on Divergent Thinking and Creative Outcomes. Proceedings of Academy of Management, Honolulu, Hawaii, 17.

13. Compeau, D., Gravill, J., Haggerty, N., \& Kelley, H., "Computer Self-Efficacy: A Review," in P. Zhang and D. Galletta, ed., Human-Computer Interaction and Management Information Systems - Foundations., Vol. 4, Advanced in Management Information Systems, Armonk, NY: M.E. Sharpe, Inc., 2006.

14. Compeau, D. R. \& Higgins, C. A. (1995). Computer self-efficacy: Development of a measure and initial test. MIS Quarterly, 19,(2), 189.
15. Cooper, R. B. (2000). Information Technology Development Creativity: A Case Study of Attempted Radical Change. MIS Quarterly, 24,(2), 245.

16. Couger, J. D. (1996). Creativity and Innovation in Information Systems Organizations, Danvers, MA: Boyd and Fraser.

17. Couger, J. D. (1998). Key Human Resource Issues in the 1990s: Views of IS Executives versus Human Resource Executives. Information and Management, 14,(4), 161-174.

18. Coulson, L. \& Strickland, A. (1991). Applied Creativity. Executive Excellence, 8, 8-9.

19. Csikzentmihalyi, M. (1975). Beyond Boredom and Anxiety, San Francisco: Jossey-Bass.

20. Curtis, B., Krasner, H., \& Iscoe, N. (1988). A Field Study of the Software Design Process for Large Systems. Communications of the ACM, 31,(11), 1268-1287.

21. DeLone, W. H. \& McLean, E. R. (1992). Information Systems Success: The Quest for the Dependent Variable. Information Systems Research, 3,(1), 60-95.

22. Ford, C. M. (1996). A Theory of Individual Creative Action in Multiple Social Domains. Academy of Management Review, 21,(4), 11121142.

23. Ford, C. M. \& Gioia, D. A. (2000). Factors Influencing Creativity in the Domain of Managerial Decision Making. Journal of Management, 26,(4), 705-732.

24. Gilliam, T. K. (1993). Managing the power of creativity. Bank Marketing, 25,(12), 14.

25. Glynn, M. A. \& Webster, J. e. (1992). The adult playfulness scale: An initial assessment. Psychological Reports, 71,(1), 83.

26. Gray, P. (2007). Where Will Tomorrow's (And Even Today's) IS Workers Come From? Information Systems Management, 24,(1), 99.

27. LaCapra, L. T., "Ireland Looks to U.S. in Search of Skilled Workers," Wall Street Journal, 2006, p. B.4.

28. Levy, J. (1983). Play Behavior, Malabar, FL: Krieger.

29. Marakas, G. M., Yi, M. Y., \& Johnson, R. D. (1998). The Multilevel and Multifaceted Character of Computer Self-Efficacy: Toward Clarification of the Construct and an Integrative Framework for Research. Information Systems Research, 9,(2), 126-163.

30. Martocchio, J. J. \& Webster, J. (1992). Effects of Feedback and Cognitive Playfulness on Performance in Microcomputer Software Training. Personnel Psychology, 45,(3), 553578. 
31. Massetti, B. (1996). An empirical examination of the value of creativity support systems on idea generation. MIS Quarterly, 20,(1), 83.

32. NetworkWorld. (2007). Layoffs. Accessed at: http://www.networkworld.com/topics/layoffs.ht ml. Last accessed on: March 15, 2007.

33. Niederman, F. \& Brancheu, J. C. (1991). Information Systems Management Issues for the 1990s. MIS Quarterly, 15,(4), 475-500.

34. Palvia, P. C. \& Basu, S. C. (1999). Information Systems Management Issues: Reporting and Relevance. Decision Sciences, 30,(1), 273-290.

35. Perry-Smith, J. E. \& Shalley, C. E. (2003). The Social Side of Creativity: A Static and Dynamic Social Network Perspective. Academy of Management Review, 28,(1), 89-106.

36. Ravichandran, T. \& Rai, A. (2000). Quality Management in Systems Development: An Organizational System Perspective. MIS Quarterly, 24,(3), 381-415.

37. Ravichandran, T. \& Rai, A. (2003). Structural Analysis of the Impact of Knowledge Creation and Knowledge Embedding on Software Process Capability. IEEE Transactions on Engineering Management, 50,(3), 270-284.

38. Robillard, P. N. (1999). The Role of Knowledge in Software Development. Communications of the ACM, 42,(1), 87-92.

39. Satzinger, J. W., Garfield, M. J., \& Nagasundaram, M. (1999). The Creative Process: The Effects of Group Memory on Individual Idea Generation. Journal of Management Information Systems, 15,(4), 143160.

40. Starbuck, W. H. \& Webster, J. (1991). When is Play Productive? Accounting, Management and Information Technology, 1,(1), 71-90.

41. Surakka, S. (2007). What Subjects and Skills are Important for Software Developers? Communications of the ACM, 50,(1), 73-78.

42. Tierney, P. \& Farmer, S. M. (2002). Creative Self-Efficacy: Its Potential Antecedents and Relationship to Creative Performance. Academy of Management Journal, 45,(6), 1137-1148.

43. Tierney, P. \& Farmer, S. M. (2004). The Pygmalion Process and Employee Creativity. Journal of Management, 30,(3), 413-432.

44. Tiwana, A. \& McLean, E. R. (2005). Expertise Integration and Creativity in Information Systems Development. Journal of Management Information Systems, 22,(1), 13-43.

45. Venkatesh, V., Morris, M. G., Davis, G. B., \& Davis, F. D. (2003). User Acceptance of Information Technology: Toward A Unified View. MIS Quarterly, 27,(3), 425-478.
46. Walz, D., Elam, J., \& Curtis, B. (1993). Inside a Software Design Team: Knowledge Acquisition, Sharing, and Integration. Communications of the ACM, 36,(10), 63-77.

47. Wang, A.-c., Cheng, B.-S., \& Farh, J.-L. (2005). The Influence of Transformational Leadership and Core Self-Evaluations on Individual Creativity. Proceedings of Academy of Management, Honolulu, Hawaii, 55.

48. Webster, J. \& Marrocchio, J. J. (1993). Turning Work into Play: Implications for Microcomputer Software Training. Journal of Management, 19,(1), 127.

49. Webster, J. \& Martocchio, J. J. (1992). Microcomputer playfulness: Development of a measure with workplace implications. MIS Quarterly, 16,(2), 201-226.

50. Wierenga, B. \& Van Bruggen, G. H. (1998). The Dependent Variable in Research Into the Effects of Creativity Support Systems: Quality and Quantity of Ideas. MIS Quarterly, 22,(1), 81-87.

\footnotetext{
${ }^{a}$ Our use of the term IS personnel or IS workers refers to personnel connected with IS development, or software developers.
} 